\title{
Filtration and transport of heavy metals in graphene oxide enabled sand columns
}

\author{
Zhuhong Ding, Xin Hu, Verónica L. Morales, Bin Gao
}

NOTICE: this is the author's version of a work that was accepted for publication in Chemical Engineering Journal. Changes resulting from the publishing process, such as peer review, editing, corrections, structural formatting, and other quality control mechanisms may not be reflected in this document. Changes may have been made to this work since it was submitted for publication. A definitive version was subsequently published in Chemical Engineering Journal, [Vol. 257, (2014)] DOI http://dx.doi.org/10.1016/j.cej.2014.07.034 
Short communication

Filtration and transport of heavy metals in graphene oxide enabled sand columns

Zhuhong Ding ${ }^{\mathrm{a}, \mathrm{b}}, \mathrm{Xin} \mathrm{Hu}^{\mathrm{c}, \mathrm{b}}$, Verónica L. Morales ${ }^{\mathrm{d}}, \mathrm{Bin} \mathrm{Gao}^{\mathrm{b}} *$

${ }^{a}$ School of Environment, Nanjing Tech University, Nanjing, 211816, PR China

${ }^{b}$ Department of Agricultural and Biological Engineering, University of Florida, Gainesville, FL 32611-0570, United States

${ }^{c}$ State Key Laboratory of Analytical Chemistry for Life Science, Center of Material Analysis and School of Chemistry and Chemical Engineering, Nanjing University, Nanjing 210093, P.R. China

${ }^{d}$ SIMBIOS Centre, University of Abertay, Dundee, DDI U.K.

*Corresponding author, phone: (352) 392-1864 ext. 285, Fax: (352) 392-4092, email:

bg55@ufl.edu 


\section{Abstract}

A fixed-bed sand column with graphene oxide (GO) layer was used to remove heavy metals $(\mathrm{Cu}(\mathrm{II})$ and $\mathrm{Pb}(\mathrm{II}))$ from an aqueous solution injected under steady flow. Due to the time constrained kinetic process of heavy metal sorption to GO, removal efficiency was affected by the injection flow rate. When injection flow rate changed from 1 to $5 \mathrm{~mL} \cdot \mathrm{min}^{-1}$, the removal efficiency of the two metals decreased from $15.3 \%$ to $10.3 \%$ and from $26.7 \%$ to $19.0 \%$ for $\mathrm{Cu}$ (II) and $\mathrm{Pb}(\mathrm{II})$, respectively. Provided a fixed concentration of heavy metals in the injected flow, an increase in GO in column from 10 to $30 \mathrm{mg}$ resulted in an sharp increase in the removal efficiency of $\mathrm{Pb}$ (II) from $26.7 \%$ to $40.5 \%$. When $\mathrm{Cu}$ (II) and $\mathrm{Pb}$ (II) were applied simultaneously, the removal efficiency of the two metals was lower than when applied by individually. GO-sand column performance was much better for the removal of $\mathrm{Pb}(\mathrm{II})$ than for $\mathrm{Cu}(\mathrm{II})$ in each corresponding treatment. When breakthrough curve (BTC) data were simulated by the convection-dispersion-reaction (CDER) model, the fittings for $\mathrm{Cu}$ in every treatment were better than that of $\mathrm{Pb}$ in corresponding treatment. Considering the small amount of GO used to enable the sand columns that resulted in a great increase in $k$ value, compared to the GO-free sand columns, the authors propose $\mathrm{GO}$ as an effective adsorption media in filters and reactive barriers to remove $\mathrm{Pb}(\mathrm{II})$ from flowing water.

Keywords: Graphene oxide; Fixed-bed column; Filtration; $\mathrm{Cu} ; \mathrm{Pb}$ 


\section{Introduction}

Lack of clean water resources has become a highly pervasive worldwide problem due to rapid urbanization and industrialization [1]. A growing number of contaminants have direct entryways into freshwater resources, causing numerous environmental and health problems. There is therefore a need to find innovative and cost-effectively solutions to water purification and wastewater reutilization with new materials and techniques [1]. As a derivative of graphene nanosheets, graphene oxide $(\mathrm{GO})$ has become one of the most intensively studied engineered nanomaterials in the last decade due to its tremendous potential in environmental applications; particularly with respect to water purification [2-5]. It has been reported in the literature that GO and GO-based sorbents have strong sorption ability to various water contaminants, including heavy metals and organic pollutants [6-9].

GO has a sheet structure with an abundance of oxygen atoms on the graphitic backbone in the form of epoxy, hydroxyl, and carboxyl functional groups [10]. These functional groups are the essential chemical skeletons for an ideal adsorbent of heavy metals because of their strong affinity to cations, especially multivalent metal ions [11-13], through both electrostatic and coordinate approaches [14].

Laboratory batch sorption experiments have been used to determine the sorption ability of GO to a variety of heavy metal ions, including $\mathrm{Pb}(\mathrm{II}), \mathrm{Cu}(\mathrm{II}), \mathrm{Cd}(\mathrm{II}), \mathrm{Co}(\mathrm{II}), \mathrm{Zn}$ (II), $\mathrm{Eu}(\mathrm{III})$, and Th(IV) in aqueous solutions [15-18]. Most of these studies were focused on exploring the 
sorption characteristics and mechanisms of GO to heavy metals in single sorbate solution systems. Only few studies have examined the competitive sorption of different heavy metals on GO in aqueous solutions [16]. Findings from the batch sorption studies have demonstrated the great potential of using $\mathrm{GO}$ as an effective sorbent to remove heavy metals from water. Because almost all batch sorption experiments are conducted under ideal sorption conditions (e.g., full contact and sufficient reaction time), fix-bed adsorption experiments are often used to evaluate the sorbents as packed media in filter systems [19-21]. In the literature, however, only few studies have investigated the filtration of heavy metals by GO enabled fix-bed columns [3].

In general, engineered nanomaterials, including GO, may not be applied directly as filter media because of their small size. To take advantage of the great sorption ability of engineered nanomaterials, several methods have been developed to combine them with other sorbents such as sand for improved filter performance [3, 19, 20, 22-24]. For example, Gao et al. [3] found that GO can be used to coat sand surfaces and the GO-enabled sand retains at least 5-fold higher concentration of heavy metal and organic dye than pure sand. Recently, Tian et al. [19, 20] evaluated the effect of different packing methods of carbon nanotubes (CNTs) in sand columns on their removal of heavy metals and antibiotics from aqueous solutions and found that CNT packed together with natural sand can effectively and safely remove metallic and pharmaceutical contaminants from water. Furthermore, their results also suggested that functionalized carbon nanomaterials may be applied as a layer within natural sand columns to filter contaminants from 
water.

The overarching objective of this work was to determine the removal efficiency of GO-enabled sand filters for aqueous heavy metal cations. GO-enabling consisted of thin layering of GO material in a quartz sand bed to create the fixed-column. The filtration and transport of $\mathrm{Pb}(\mathrm{II})$ and $\mathrm{Cu}(\mathrm{II})$ in $\mathrm{GO}$-enabled and pure sand columns (the control) were investigated under various conditions. The specific objectives were as follows: 1) determine the effect of GO on the removal of two types of heavy metals in the fix-bed sand columns under single and dual sorbate conditions; 2) determine the effect of flow rate and GO loading on heavy metal removal; and 3) model the filtration and transport of heavy metals in the fix-bed columns.

\section{Materials and methods}

\subsection{Materials}

GO was obtained from ACS Material (Medford, MA) and used as received. According to the manufacturer, it was prepared by the modified hummer's method. The physical dimensions of GO were determined previously, where an average thickness and average square root of the area was reported as $0.92 \pm 0.13 \mathrm{~nm}$ and $582 \pm 111.2 \mathrm{~nm}$, respectively [25]

Quartz sand (Standard Sand \& Silica Co.) of grain size $0.5-0.6 \mathrm{~mm}$ was washed sequentially with tap water, $10 \%$ nitric acid (v:v), and deionized (DI) water, followed by oven drying at $70^{\circ} \mathrm{C}$ following the procedure of Tian et al. [26] to remove loose impurities and metal oxides. 
Copper nitrate and lead nitrate were used to prepare the heavy metal stock solutions. Individual metal solutions were prepared at concentrations of $10 \mathrm{mg} \mathrm{L}^{-1}$ of $\mathrm{Cu}^{2+}$ or $\mathrm{Pb}^{2+}$. In addition, a dual metal solution containing $10 \mathrm{mg} \mathrm{L}^{-1}$ of $\mathrm{Cu}^{2+}$ and $\mathrm{Pb}^{2+}$, each, was also prepared. Inductively coupled plasma optical emission spectrometry (ICP-OES, Optima 2100 DV, PerkinElmer Inc., Waltham, MA) was used to determine the metal concentration in the solutions. Nitric acid and sodium hydroxide solutions were used to adjust the $\mathrm{pH}$ of the metal solutions to 5.6.

\subsection{Fixed-bed column experiment}

Fixed-bed column experiments were used to quantitatively evaluate the removal of heavy metals dissolved in water. GO was packed as a thin layer in the middle of the fixed-bed contained in an acrylic column $(1.5 \mathrm{~cm}$ inside diameter and $5 \mathrm{~cm}$ height) holding approximately $16.5 \mathrm{~g}$ of quartz sand (Table 1). Packing of the GO-enable fixed-bed column entailed filling half of column with sand by wet-packing into the acrylic column, carefully layering 10 or $30 \mathrm{mg}$ of GO on top of the packed sand, and finally wet-packing the rest of the sand into the column. Membranes with $50 \mathrm{~lm}$ pores (Spectra/Mesh, Spectrum Laboratories, Inc.) were used at the column inlet and outlet to distribute the flow and seal the column. Sand columns packed without GO were also prepared to be used as controls. Because only small amount of GO $(0.06 \%$ w/w or $0.18 \% \mathrm{w} / \mathrm{w}$ of $\mathrm{GO} / \mathrm{sand}$ ) were used in the fixed-bed columns, the bed porosity of all the columns 
was assumed to remain at 0.45 .

After packing, the columns were first flushed with DI water ( $\mathrm{pH} 5.6$, adjusted with nitric acid) for $1 \mathrm{~h}$ to remove potential impurities. They were then subjected to pulses of single or dual metal solutions and the removal efficiency was determined through mass balance calculations. Figure 1 illustrates the setup of the fix-bed column experiment. The BTC experiments consisted of two injection stages. At stage one, the single $(\mathrm{Cu}(\mathrm{II})$ or $\mathrm{Pb}(\mathrm{II}))$ or dual $(\mathrm{Cu}(\mathrm{II})$ and $\mathrm{Pb}(\mathrm{II}))$ metal solutions were injected into the bottom of the column at a steady flow rate $\left(1 \mathrm{~mL} \cdot \mathrm{min}^{-1}\right.$ or 5 $\mathrm{mL} \cdot \mathrm{min}^{-1}$ ) for 28 or $140 \mathrm{~min}$. At stage two, the influent was switched to metal-free DI water for an additional $2 \mathrm{~h}$ to elute residual heavy metals in the pore water. Effluent samples were collected discretely with a fraction collector and the metal concentrations were measured with the ICP-OES. All treatments were tested in duplicate, and average values were reported.

\subsection{Model heavy metal transport in the columns}

Filtration and transport of the heavy metals in the GO-enabled and pure sand columns were simulated by the convection-dispersion-reaction (CDER) model. The governing equation can be written as [27]:

$R \frac{\partial C}{\partial t}+\frac{\rho_{b}}{\theta} \frac{\partial q}{\partial t}=D \frac{\partial^{2} C}{\partial z^{2}}-v \frac{\partial C}{\partial z}$

$\frac{\rho_{b}}{\theta} \frac{\partial q}{\partial t}=k C$

where $R$ is the retardation factor (dimensionless), $C$ is the sorbate concentration in pore water 
$\left(\mathrm{mg} \mathrm{L}^{-1}\right), t$ is time (min), $\rho_{b}$ is the medium bulk density $\left(\mathrm{g} \mathrm{L}^{-1}\right), \theta$ is the dimensionless volumetric moisture content, $q$ is the concentration of heavy metal adsorbed onto the column (as sand or sand+GO combination) $\left(\mathrm{mg} \mathrm{g}^{-1}\right), z$ is the distance traveled in the direction of flow $(\mathrm{cm}), D$ is the dispersion coefficient $\left(\mathrm{cm}^{2} \mathrm{~min}^{-1}\right), v$ is the average linear pore-water velocity $\left(\mathrm{cm} \mathrm{min}^{-1}\right)$, and $k$ is the first-order removal rate constant $\left(\mathrm{min}^{-1}\right)$. Equations (1) and (2) were solved numerically using the finite difference method with a zero initial concentration, a pulse-input and a zero-concentration-gradient boundary conditions for the whole column. The Levenberg-Marquardt algorithm was used to estimate the value of the model parameters by minimizing the sum-of-the-squared differences between model-calculated and measured effluent concentrations over multiple calculation iterations.

\section{Results and discussion}

Removal of dissolved metals from water was evaluated through analysis of experimental effluent breakthrough concentration. BTCs in Figures 2-5 were constructed as plots of the application time of liquid versus the normalized concentration $\left(\mathrm{C} / \mathrm{C}_{0}\right)$ of the injected metal in the effluent.

\subsection{Effect of flow rate}

Breakthrough curves (BTCs) and removal efficiency values for single metal pulse injections 
were compared for fixed-bed columns with and without GO at two different effluent flow rates, as illustrated in Table 1, and Figures 2 and 3, which showed that the addition of GO enhanced the removal of heavy metals in the columns. Peak effluent concentrations for $\mathrm{Cu}$ (II) and $\mathrm{Pb}$ (II) of the single injection to columns enabled with $10 \mathrm{mg}$ of GO were measured at 0.94 and 0.86 for the $1 \mathrm{~mL} \cdot \mathrm{min}^{-1}$ flow rate experiments and 0.95 and 0.90 for the $5 \mathrm{~mL} \cdot \mathrm{min}^{-1}$ flow rate experiments, respectively. The authors expected that an increase in contact time between the metal solution and the GO adsorbent at the lower flow rate would enhance removal efficiency of the fixed-bed columns. As presented in Table 1, the removal efficiency of the two metals decreased from $15.3 \%$ to $10.3 \%$ and from to $26.7 \%$ to $19.0 \%$ for the single injection of $\mathrm{Cu}(\mathrm{II})$ and $\mathrm{Pb}$ (II), respectively, as the injection flow rate was raised from 1 to $5 \mathrm{~mL} \mathrm{~min}^{-1}$. Presumably this trend is due to the reduced contact time between dissolved metals and the GO layer. Furthermore, the observed removal efficiencies suggest that the association of $\mathrm{Pb}$ to $\mathrm{GO}$ is greater than that of $\mathrm{Cu}$ (Table 1), an observation that is in agreement with previous reports that the affinities of GO for the metal ions follow the order of $\mathrm{Pb}(\mathrm{II})>\mathrm{Cu}(\mathrm{II})>>\mathrm{Cd}(\mathrm{II})>\mathrm{Zn}$ (II) in batch experiment [16].

\subsection{Effect of GO loading}

To test the effect of GO dosing on removal efficiency, experiments in fixed-bed columns enabled with $30 \mathrm{mg}$ of GO were also conducted at a flow rate of $1 \mathrm{~mL} \mathrm{~min}^{-1}$ (Figures 4). As shown in Table 1 , the final values of $\mathrm{C} / \mathrm{C}_{0}$ for $\mathrm{Cu}$ (II) at the end of metal solution injection were 
1, 0.94 and 0.89 for 0,10 and $30 \mathrm{mg}$ of GO in the fixed-bed, respectively. Similarly, final values for $\mathrm{Pb}$ (II) were $1,0.86$ and 0.76 for the same GO gradation. Such trends indicate a higher saturation capacity of the column with increasing GO amount for both types of metal. Removal efficiency for $\mathrm{Cu}(\mathrm{II})$ increased from $4.2 \%$, to $15.3 \%$ to $19.6 \%$ with increasing amount of GO in the column from 0 to 10 to $30 \mathrm{mg}$. For $\mathrm{Pb}(\mathrm{II})$, this increased from $11.3 \%$ to $26.7 \%$ to $40.5 \%$. From the removal efficiency trends, it is evident that the removal of $\mathrm{Pb}$ is affected more significantly than that of $\mathrm{Cu}(\mathrm{II})$ with the same amount of GO used to enable the fixed-bed.

\subsection{Dual metal removal}

Dual metal ion solutions were used to test for sorption site competition in $10 \mathrm{mg}$ GO-enabled fixed-bed columns at a flow rate of $1 \mathrm{~mL} \mathrm{~min}^{-1}$. The peak effluent $\mathrm{C} / \mathrm{C}_{0}$ values at the end of the metal solution injection for $\mathrm{Cu}$ (II) and $\mathrm{Pb}$ (II) approached 0.94 and 0.92 , respectively. Removal efficiency values in the dual-metal solution injection were consistently lower $(11.8 \%$ and $23.3 \%$ for $\mathrm{Cu}(\mathrm{II})$ and $\mathrm{Pb}(\mathrm{II})$, respectively) than for the single-metal treatments $(15.3 \%$ and $26.7 \%$ for $\mathrm{Cu}(\mathrm{II})$ and $\mathrm{Pb}(\mathrm{II})$, respectively), including the GO-free controls (Table 1). Similar to the trends observed in the single-metal treatments, $\mathrm{Pb}(\mathrm{II})$ demonstrated to have higher removal efficiency by mas than $\mathrm{Cu}(\mathrm{II})$ by $\mathrm{GO}$ in the dual-metal experiments.

\subsection{Model results}


The model was applied to the BTCs with the known parameters (i.e., $\rho_{b}=1630 \mathrm{~g} \mathrm{~L}^{-1}, \theta=$ $0.45, D=0.062 \mathrm{~cm}^{2} \mathrm{~min}^{-1}$, and $v=1.26 / 6.28 \mathrm{~cm} \mathrm{~min}^{-1}$ ) and the best-fit $R$ and $k$ values (Table 1). The $\mathrm{Cu}(\mathrm{II}) \mathrm{BTCs}$ in all treatments were well described by the model $\left(\mathrm{R}^{2} \geq 0.90\right)$, while $\mathrm{Pb}(\mathrm{II})$ BTCs were fitted less well $\left(\mathrm{R}^{2} \geq 0.70\right)$. The authors speculate that this discrepancy in model fitting between the two metals may be due to the greater affinity of $\mathrm{GO}$ to $\mathrm{Pb}$ (II) than for $\mathrm{Cu}$ (II), as well as the improper assumption of an homogeneous bed medium for the actual layer of GO sorbent in the column. Moreover, the goodness of fit decreases with increasing amount of GO to a greater extent for $\mathrm{Pb}(\mathrm{II})$ than for $\mathrm{Cu}(\mathrm{II})$.

Estimated values for the first-order removal rate, $k$, were consistently greater for $\mathrm{Pb}$ (II) than $\mathrm{Cu}(\mathrm{II})$ in comparable treatments, suggesting that the removal of $\mathrm{Pb}(\mathrm{II})$ under 'clean-bed' conditions was faster than the removal of $\mathrm{Cu}(\mathrm{II})$. Although the increase in flow rate resulted in lower metal removal, the estimated $k$ values for both metals tended to increase because flow velocity strongly affect the adsorption kinetics. The increase in GO applied amount resulted in larger $R$ and $k$ values for both metals with a more pronounced effect for $\mathrm{Pb}(\mathrm{II})$, indicating faster and more efficient removal of $\mathrm{Pb}$ (II). When $\mathrm{Cu}$ (II) and $\mathrm{Pb}$ (II) were applied together, $k$ values decreased as compared to their individual application, indicating a clear competition in adsorption sites between the two metal species.

\section{Conclusions}


Graphene oxide has been heavily proposed as a promising sorbent for heavy metal in aqueous solutions due to its chemical functionality, fast sorption kinetics, and evidence for high affinity for heavy metals in isotherm studies. However, to the knowledge of the authors, adsorption/filtration of heavy metals using layered GO in fix-bed has not been investigated. In this study, heavy metals ( $\mathrm{Pb}(\mathrm{II})$ and $\mathrm{Cu}(\mathrm{II}))$ in aqueous solutions were adsorbed by a thin layer of GO in fix-bed sand column. An increase in injection flow rate was deemed to decrease the removal efficiency of both metal species. Conversely, an increase in the amount of GO to enable the fixed-bed column resulted in the expected improvement of heavy meal removal, especially for $\mathrm{Pb}(\mathrm{II})$. Dual-metal solution treatments provided evidence of metal competition for adsorption sites when multiple species were present in injection solution, thus resulting in lower removal efficiency of each individual metal than when applied as single-metal solutions. GO-sand column performance was generally better for the removal of $\mathrm{Pb}$ (II) than $\mathrm{Cu}(\mathrm{II})$. CDER model fit was better for $\mathrm{Cu}$ than $\mathrm{Pb}$ in corresponding treatments. An increase in the $\mathrm{GO}$ amount used to enable the column generated BTC data that was less well fit by the same CDER. This poorer fit may, ostensibly be due to the invalid assumption of a homogeneous medium, as it is know that the affinity of GO to heavy metals is much greater than that of sand, therefore creating chemical heterogeneity in the GO-layered sand column.

Considering the small amount of GO required to enable the sand columns to greatly improve their filtration capacity and adsorption rate, this study recommends GO-enabling of filters and 
reactive barriers to enhance filtration of heavy metals from flow-through aqueous solutions.

\section{Acknowledgment}

This work was partially supported by the NSFC (21007026) and the NSF (CHE1213333). Z.

Ding thanks for the sponsor of the Jiangsu Overseas Research \& Training Program. V.L. Morales

acknowledges support from the Marie Curie Actions-International Incoming Fellowship (FP7-PEOPLE-2012-SoilArchnAg). 


\section{References}

[1] M.A. Shannon, P.W. Bohn, M. Elimelech, J.G. Georgiadis, B.J. Marinas, A.M. Mayes, Science and technology for water purification in the coming decades, Nature, 452 (2008) 301-310.

[2] H.Y. Fu, D.Q. Zhu, Graphene oxide-facilitated reduction of nitrobenzene in sulfide-containing aqueous solutions, Environ. Sci. Technol., 47 (2013) 4204-4210.

[3] W. Gao, M. Majumder, L.B. Alemany, T.N. Narayanan, M.A. Ibarra, B.K. Pradhan, P.M. Ajayan, Engineered graphite oxide materials for application in water purification, Acs Applied Materials \& Interfaces, 3 (2011) 1821-1826.

[4] R.K. Joshi, P. Carbone, F.C. Wang, V.G. Kravets, Y. Su, I.V. Grigorieva, H.A. Wu, A.K. Geim, R.R. Nair, Precise and ultrafast molecular sieving through graphene oxide membranes, Science, $343(2014) 752-754$.

[5] P.Z. Sun, M. Zhu, K.L. Wang, M.L. Zhong, J.Q. Wei, D.H. Wu, Z.P. Xu, H.W. Zhu, Selective ion penetration of graphene oxide membranes, Acs Nano, 7 (2013) 428-437.

[6] X.M. Ren, J.X. Li, X.L. Tan, X.K. Wang, Comparative study of graphene oxide, activated carbon and carbon nanotubes as adsorbents for copper decontamination, Dalton Transactions, 42 (2013) 5266-5274.

[7] H. Chen, B. Gao, H. Li, Functionalization, ph, and ionic strength influenced sorption of sulfamethoxazole on graphene, Journal of Environmental Chemical Engineering, 2 (2014) 
310-315.

[8] M. Zhang, B. Gao, X.D. Cao, L.Y. Yang, Synthesis of a multifunctional graphene-carbon nanotube aerogel and its strong adsorption of lead from aqueous solution, Rsc Advances, 3 (2013) 21099-21105.

[9] M. Zhang, B. Gao, Y. Li, X.W. Zhang, I.R. Hardin, Graphene-coated pyrogenic carbon as an anode material for lithium battery, Chem. Eng. J., 229 (2013) 399-403.

[10] D.R. Dreyer, S. Park, C.W. Bielawski, R.S. Ruoff, The chemistry of graphene oxide, Chem. Soc. Rev., 39 (2010) 228-240.

[11] C.J. Madadrang, H.Y. Kim, G.H. Gao, N. Wang, J. Zhu, H. Feng, M. Gorring, M.L. Kasner, S.F. Hou, Adsorption behavior of edta-graphene oxide for pb (ii) removal, Acs Applied Materials \& Interfaces, 4 (2012) 1186-1193.

[12] C. Xu, X. Wang, L.C. Yang, Y.P. Wu, Fabrication of a graphene-cuprous oxide composite, J. Solid State Chem., 182 (2009) 2486-2490.

[13] M. Machida, T. Mochimaru, H. Tatsumoto, Lead(ii) adsorption onto the graphene layer of carbonaceous materials in aqueous solution, Carbon, 44 (2006) 2681-2688.

[14] S.T. Yang, Y.L. Chang, H.F. Wang, G.B. Liu, S. Chen, Y.W. Wang, Y.F. Liu, A.N. Cao, Folding/aggregation of graphene oxide and its application in cu2+ removal, J. Colloid Interf. Sci, $351(2010)$ 122-127.

[15] Y. Sun, Q. Wang, C. Chen, X. Tan, X. Wang, Interaction between eu(iii) and graphene oxide 
nanosheets investigated by batch and extended x-ray absorption fine structure spectroscopy and by modeling techniques, Environ. Sci. Technol., 46 (2012) 6020-6027.

[16] R. Sitko, E. Turek, B. Zawisza, E. Malicka, E. Talik, J. Heimann, A. Gagor, B. Feist, R. Wrzalik, Adsorption of divalent metal ions from aqueous solutions using graphene oxide, Dalton Transactions, 42 (2013) 5682-5689.

[17] G. Zhao, J. Li, X. Ren, C. Chen, X. Wang, Few-layered graphene oxide nanosheets as superior sorbents for heavy metal ion pollution management, Environ. Sci. Technol., 45 (2011) 10454-10462.

[18] N. Pan, D. Guan, T. He, R. Wang, I. Wyman, Y. Jin, C. Xia, Removal of th ${ }^{4+}$ ions from aqueous solutions by graphene oxide, J. Radioanal. Nucl. Ch., 298 (2013) 1999-2008.

[19] Y. Tian, B. Gao, V.L. Morales, H. Chen, Y. Wang, H. Li, Removal of sulfamethoxazole and sulfapyridine by carbon nanotubes in fixed-bed columns, Chemosphere, 90 (2013) 2597-2605.

[20] Y. Tian, B. Gao, V.L. Morales, L. Wu, Y. Wang, R. Munoz-Carpena, C. Cao, Q. Huang, L. Yang, Methods of using carbon nanotubes as filter media to remove aqueous heavy metals, Chem. Eng. J., 210 (2012) 557-563.

[21] X.Y. Xu, X.D. Cao, L. Zhao, H.L. Wang, H.R. Yu, B. Gao, Removal of cu, zn, and cd from aqueous solutions by the dairy manure-derived biochar, Environ. Sci. Pollut. R, 20 (2013) $358-368$.

[22] S.K. Brar, M. Verma, R.D. Tyagi, R.Y. Surampalli, Engineered nanoparticles in wastewater 
and wastewater sludge - evidence and impacts, Waste Manage., 30 (2010) 504-520.

[23] V. Gupta, V. Saini, N. Jain, Adsorption of as (iii) from aqueous solutions by iron oxide-coated sand, J. Colloid Interf. Sci, 288 (2005) 55-60.

[24] N. Boujelben, J. Bouzid, Z. Elouear, M. Feki, Retention of nickel from aqueous solutions using iron oxide and manganese oxide coated sand: Kinetic and thermodynamic studies, Environ. Sci. Technol., 31 (2010) 1623-1634.

[25] L. Wu, L. Liu, B. Gao, R. Munoz-Carpena, M. Zhang, H. Chen, Z. Zhou, H. Wang, Aggregation kinetics of graphene oxides in aqueous solutions: Experiments, mechanisms, and modeling, Langmuir., 29 (2013) 15174-15181.

[26] Y.A. Tian, B. Gao, C. Silvera-Batista, K.J. Ziegler, Transport of engineered nanoparticles in saturated porous media, J. Nanopart. Res., 12 (2010) 2371-2380.

[27] H. Chen, B. Gao, H. Li, L.Q. Ma, Effects of ph and ionic strength on sulfamethoxazole and ciprofloxacin transport in saturated porous media, J. Contam. Hydrol., 126 (2011) 29-36. 


\section{Figure Captions}

Figure 1. Illustration of the fix-bed column experiment

Figure 2. Transport of $\mathrm{Cu}(\mathrm{II})$ and $\mathrm{Pb}(\mathrm{II})$ in single metal solutions through fixed-bed columns with $10 \mathrm{mg}$ GO at flow rate of $1 \mathrm{~mL} \cdot \mathrm{min}^{-1}$. Symbols are experimental data and lines are model simulations.

Figure 3. Transport of $\mathrm{Cu}(\mathrm{II})$ and $\mathrm{Pb}(\mathrm{II})$ in single metal solutions through fixed-bed columns with $10 \mathrm{mg} \mathrm{GO}$ at flow rate of $5 \mathrm{~mL} \cdot \mathrm{min}^{-1}$. Symbols are experimental data and lines are model simulations.

Figure 4. Transport of $\mathrm{Cu}(\mathrm{II})$ and $\mathrm{Pb}(\mathrm{II})$ in single metal solutions through fixed-bed columns with $30 \mathrm{mg} \mathrm{GO}$ at flow rate of $1 \mathrm{~mL} \cdot \mathrm{min}^{-1}$. Symbols are experimental data and lines are model simulations.

Figure 5. Transport of $\mathrm{Cu}(\mathrm{II})$ and $\mathrm{Pb}(\mathrm{II})$ in dual metal solutions through fixed-bed columns with $10 \mathrm{mg}$ GO at flow rate of $1 \mathrm{~mL} \cdot \mathrm{min}^{-1}$. Symbols are experimental data and lines are model simulations. 
Table 1. Summary of fixed-bed column experimental data and model results

\begin{tabular}{|c|c|c|c|c|c|c|c|c|}
\hline & \multicolumn{5}{|c|}{ Experimental data } & \multicolumn{3}{|c|}{ Model results } \\
\hline & Adsorbate & $\begin{array}{c}\text { GO amount } \\
{[\mathrm{mg}]}\end{array}$ & $\begin{array}{l}\text { Flow rate } \\
{\left[\mathrm{mL} \cdot \mathrm{min}^{-1}\right]}\end{array}$ & $\begin{array}{c}\text { Pulse } \\
\text { duration } \\
{[\mathrm{min}]}\end{array}$ & $\begin{array}{c}\text { Metal removal } \\
\text { efficiency }\end{array}$ & $R$ & $k\left[\min ^{-1}\right]$ & $R^{2}$ \\
\hline \multirow{10}{*}{$\begin{array}{l}\text { Single } \\
\text { metal } \\
(\mathrm{Cu} \text { or } \mathrm{Pb})\end{array}$} & $\mathrm{Cu}$ & 0 & 1 & 140 & $4.2 \%$ & 1.85 & 0.01 & 0.98 \\
\hline & & 10 & 1 & 140 & $15.3 \%$ & 1.99 & 0.04 & 0.90 \\
\hline & & 30 & 1 & 140 & $19.6 \%$ & 1.94 & 0.05 & 0.93 \\
\hline & $\mathrm{Pb}$ & 0 & 1 & 140 & $11.3 \%$ & 2.65 & 0.02 & 0.94 \\
\hline & & 10 & 1 & 140 & $26.7 \%$ & 2.76 & 0.07 & 0.87 \\
\hline & & 30 & 1 & 140 & $40.5 \%$ & 3.00 & 0.12 & 0.70 \\
\hline & $\mathrm{Cu}$ & 0 & 5 & 28 & $1.7 \%$ & 1.89 & 0.03 & 0.99 \\
\hline & & 10 & 5 & 28 & $10.2 \%$ & 1.90 & 0.14 & 0.96 \\
\hline & $\mathrm{Pb}$ & 0 & 5 & 28 & $9.5 \%$ & 2.65 & 0.08 & 0.91 \\
\hline & & 10 & 5 & 28 & $19.0 \%$ & 2.76 & 0.31 & 0.85 \\
\hline \multirow{4}{*}{$\begin{array}{l}\text { Dual metal } \\
(\mathrm{Cu}+\mathrm{Pb})\end{array}$} & $\mathrm{Cu}$ & 0 & 1 & 140 & $3.8 \%$ & 1.86 & 0.00 & 0.99 \\
\hline & & 10 & 1 & 140 & $11.8 \%$ & 1.95 & 0.02 & 0.98 \\
\hline & $\mathrm{Pb}$ & 0 & 1 & 140 & $8.0 \%$ & 1.93 & 0.02 & 0.96 \\
\hline & & 10 & 1 & 140 & $23.3 \%$ & 2.74 & 0.05 & 0.93 \\
\hline
\end{tabular}


Figure 1

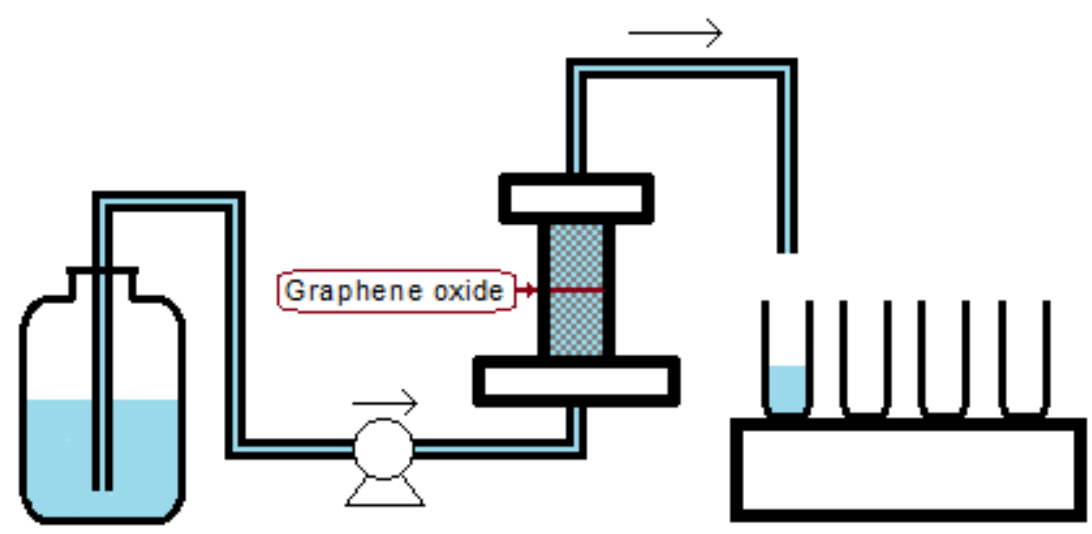




\section{Figure 2}
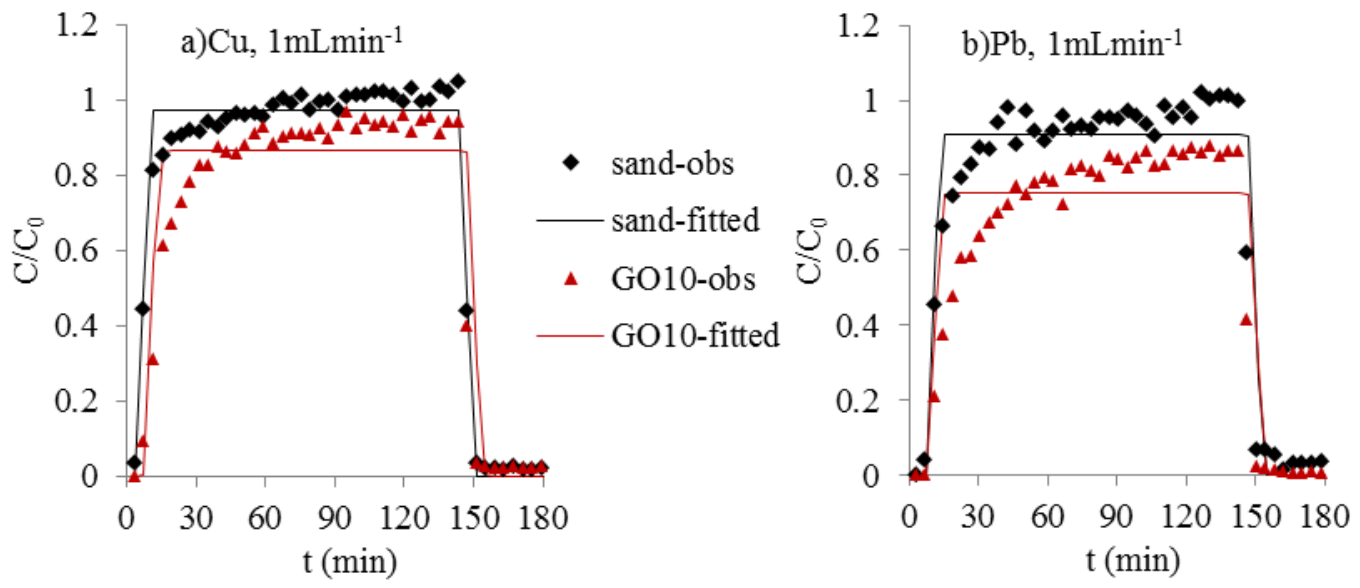
Figure 3
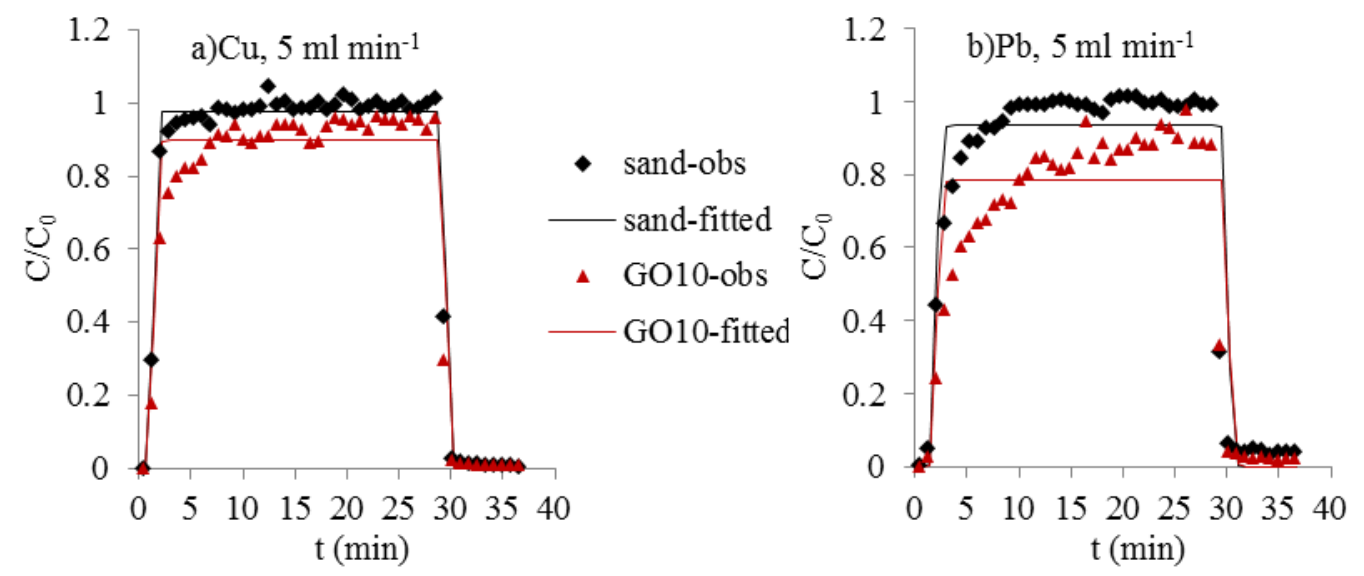


\section{Figure 4}
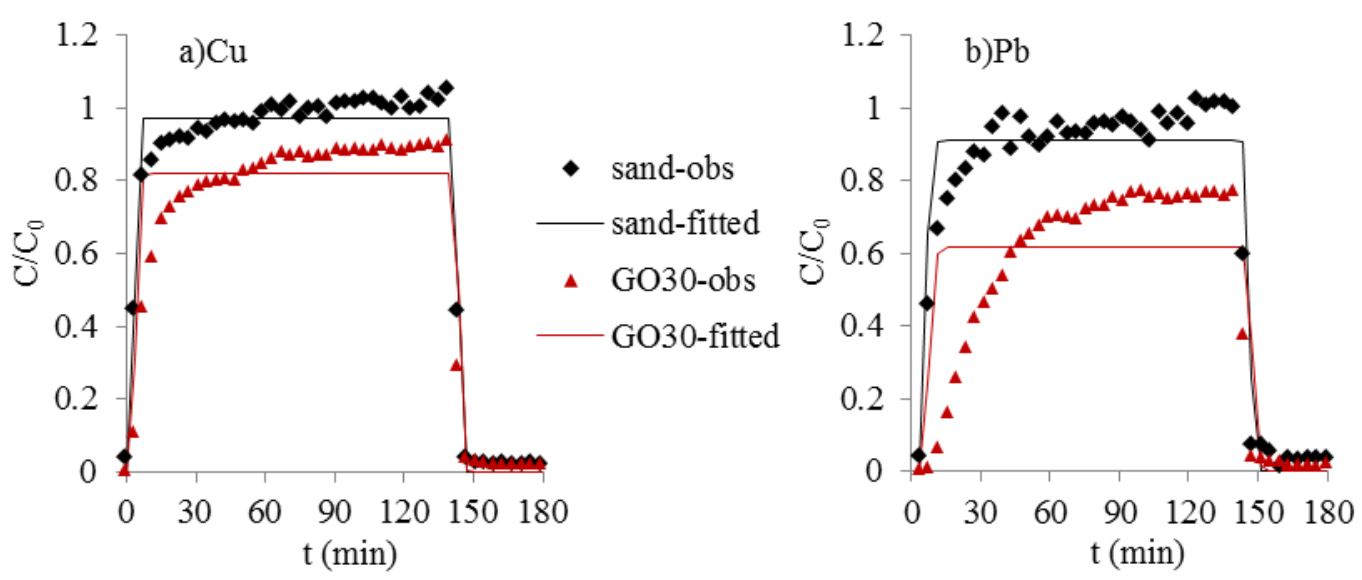
Figure 5

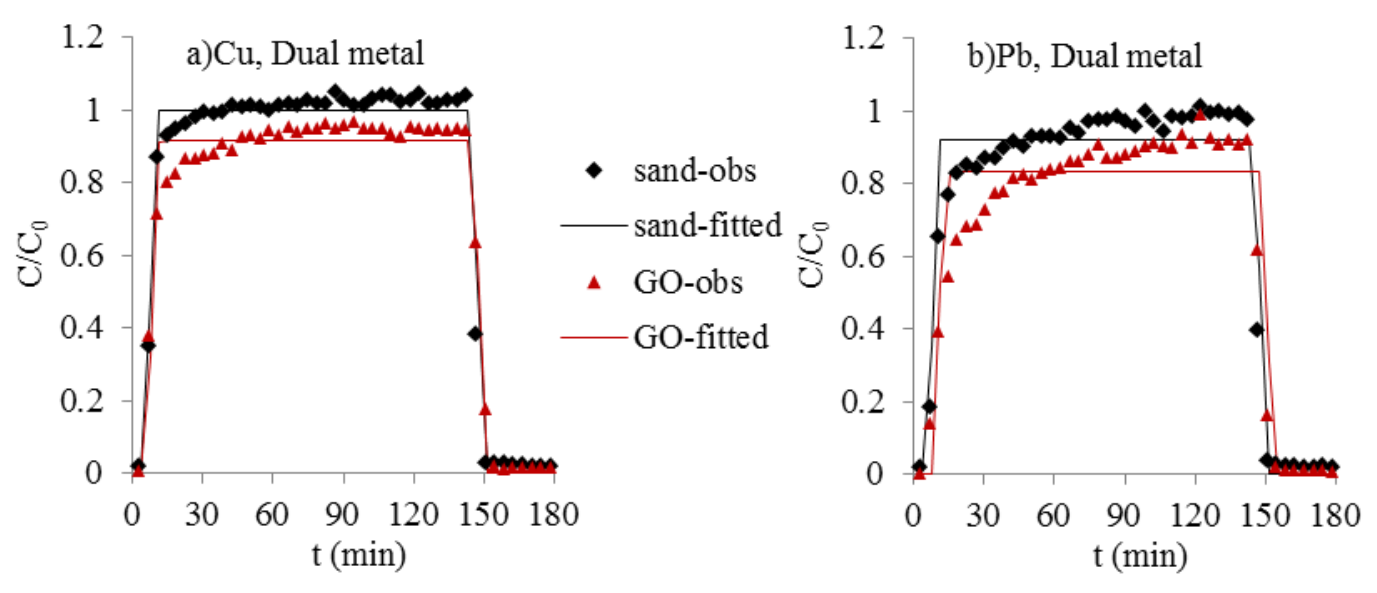

